\title{
Injuries and illnesses in a cohort of elite youth alpine ski racers and the influence of biological maturity and relative age: a two-season prospective study
}

\author{
This article was published in the following Dove Press journal: \\ Open Access Journal of Sports Medicine \\ II May 2017 \\ Number of times this article has been viewed
}

\author{
Lisa Müller' \\ Carolin Hildebrandt ${ }^{1,2}$ \\ Erich Müller ${ }^{3}$ \\ Renate Oberhoffer ${ }^{2}$ \\ Christian Raschner \\ 'Department of Sport Science, \\ University of Innsbruck, Innsbruck, \\ Austria; ${ }^{2}$ Department of Sport \\ and Health Science, Preventative \\ Pediatrics, Technical University \\ of Munich, Munich, Germany; \\ ${ }^{3}$ Department of Sport Science and \\ Kinesiology, University of Salzburg, \\ Salzburg, Austria
}

\begin{abstract}
Background: Studies on injuries and illnesses involving youth ski racers younger than 15 years are lacking in the literature. The aim of this study was prospectively to assess the incidence, prevalence, and severity of traumatic and overuse injuries, as well as illnesses of elite youth ski racers with regard to sex, biological maturity status, and relative age.

Subjects and methods: A prospective, longitudinal cohort design was used to monitor the anthropometrics, training characteristics, traumatic and overuse injuries, and illnesses of 82 elite youth ski racers (51 males, 31 females, age 9-14 years) over 2 consecutive years. The exact training exposure (skiing and athletic) was recorded. Relative age and estimated biological maturity status were assessed.
\end{abstract}

Results: Relatively low injury incidence or prevalence (traumatic, 0.86/1,000 hours of training; overuse, 0.28/1,000 hours) and comparably high illness prevalence (2.4/athlete) were reported. The knee was the most commonly affected body part (traumatic injuries $36.5 \%$, overuse injuries $82 \%$ ). A high number of bone fractures were revealed (46\%), while no stress fractures occurred; $66 \%$ of the illnesses were respiratory tract infections. No differences were found between males and females, the differing maturity groups, or relative age quartiles. Early-maturing athletes had comparably low traumatic and overuse-injury rates. Relatively younger athletes had low traumatic injury rates.

Conclusion: The injury-prevention measures implemented in the training process of youth ski racers seem to contribute to a low incidence of injury. Biological maturity status should be considered in the training process to prevent injuries in late-maturing athletes.

Keywords: traumatic and overuse injuries, health problems, youth alpine ski racing, birth quarter, biological development

\section{Introduction}

Alpine ski racing is a sport with a high risk of injury. ${ }^{1}$ Through the extensive efforts of the Fédération International de Ski (FIS), there has been an increase in data on traumatic injuries in elite, high-level alpine ski racing. ${ }^{2,3}$ Injury rates of 36.2-36.7 injuries per 100 athletes per season have been reported among World Cup athletes. ${ }^{3,4}$ The most commonly injured body part is the knee; rupture of the anterior cruciate ligament (ACL) is the most frequent traumatic injury. ${ }^{5,6}$ However, reliable collection of injury data in youth alpine ski racers remains a challenge; therefore, studies involving youth ski racers, particularly with regard to overuse injuries, are less common and represent a gap in scientific research on injury prevention in alpine ski racing. ${ }^{1}$ Additionally,
Correspondence: Lisa Müller

Department of Sport Science, University of Innsbruck, 185 Fürstenweg, Innsbruck 6020, Austria

Tel +435I 250745904

Email lisa.mueller@uibk.ac.at 
off-season and off-snow training should be investigated. ${ }^{1}$ The first step in injury prevention is to establish the extent of injury problems by examining the sport-specific incidence and severity. ${ }^{7}$ One study involving youth ski racers ( $>16$ years of age) revealed similar results to studies at the elite level. Ligament injuries in the knee were the most common, and nearly half of the injuries were classified as severe. ${ }^{8}$ High training volume, intensity, and the adolescent growth spurt represent multiple risk factors for overuse injuries in youth sport. ${ }^{9,10}$ In a 2-year retrospective study, more than half of all investigated 15- to 18-year-old ski racers had at least one overuse injury. ${ }^{11}$ Additionally, youth ski racers had significantly higher rates of anterior end-plate lesions than age-matched control subjects. ${ }^{12}$ The combination of frontal bending, lateral bending, and torsion in the loaded trunk has been found to be a potential risk factor for overuse injuries in elite ski racers. ${ }^{13}$ Given these factors, skiing-specific overuse injuries, especially in young athletes, are of particular interest, due to possible growth disturbances and long-term deformities. A further challenge in youth-sport specializations is the dual management of training programs and school education. Physiological and psychological overload combined with inappropriate regeneration may negatively affect the immune system of young athletes, leading to a higher incidence of illness. To date, no studies have reported illness data in youth alpine ski racers, even though illnesses can inhibit training adaptation if they exceed a certain frequency.

Likewise, injury prevention in youth sport includes investigation of the relationship between biological maturity status and injuries. No such studies have been undertaken in alpine ski racing. In youth soccer, no significant differences were found in the overall incidence of injury among players of differing maturity status. ${ }^{14}$ However, late-maturing athletes had a higher incidence of severe injuries than normal-maturing athletes. Additionally, in Canadian youth ice hockey, relatively older athletes were at an increased risk of injury compared to relatively younger players. ${ }^{15}$ However, the influence of relative age on injuries in alpine ski racing has not been investigated, although the relative age effect is present in all age categories at both the national and international levels ${ }^{16}$ and is influenced by biological maturity status. ${ }^{17}$

Most studies conducted to establish the extent of injuries and illness have been retrospective or based on questionnaires; ${ }^{11,18,19}$ however, recall bias associated with retrospective study designs often restricts the interpretation of injury-surveillance studies. As such, a prospective study design should be used to avoid recall biases. Therefore, the first aim of the present study was to develop a user-friendly training-and-injury database as the basis for prospective and reliable data collection. Second, prospective assessment of the incidence, prevalence, and severity of traumatic and overuse injuries, as well as illnesses, of elite youth ski racers with regard to sex, biological maturity status, and relative age should be performed. It was hypothesized that relative age and maturity status would affect the characteristics of traumatic and overuse injuries and illnesses.

\section{Subjects and methods Participants}

In total, 82 elite youth ski racers (51 males and 31 females) aged 9-14 years were included in the study. The athletes were pupils of a well-known ski boarding school, for which they had to pass an entrance exam with both skiing-specific and general physical performance tests, as well as alpine skiing-specific exercises. All athletes compete at the national junior level. Prior to the study, written informed consent was obtained from the parents of the subjects and the head coach, as well as the coaches of the single classes.

\section{Design and data collection}

A prospective, longitudinal cohort design was used to monitor anthropometrics, training characteristics, traumatic and overuse injuries, and illnesses over two consecutive seasons (2014-2015 and 2015-2016), ie, school years, which lasted from the beginning of September until the beginning of July. Prior to the study, an Internet-based database (training and injury) was developed specifically for this ski boarding school to record all relevant information with regard to training, injuries, and illnesses. For each training session (athletic and skiing), the presence or absence of each athlete and a detailed training profile were recorded by the coaches, who received detailed instruction on injury definition and explanation and how to complete the injury-and-illness surveillance sheet. The reason (illness, injury, or other) for the absence of an athlete was indicated for each training session, and certain medical information was provided (illness: major symptoms, medical attendance, fever; injury: type of injury, affected body part, reason, recurrence, treatment). This information was implemented by the member responsible in the study team. All data were systematically checked with the coaches and physiotherapists, either face-to-face or by telephone. In cases of injuries and illnesses that required medical attention, a detailed medical report was provided.

A traumatic injury was defined as injury with a sudden onset based on time loss, ${ }^{20}$ and the type of traumatic injury and affected body part were defined according to the 
injury-surveillance consensus paper of the International Olympic Committee. ${ }^{21}$ The classification of injury severity (minimal, time loss of 1-3 days; mild, 4-7 days; moderate, 8-28 days; severe, $>28$ days; injury causing end of career) was performed according to Clarsen et al. ${ }^{22}$ An overuse injury was defined as any physical complaint that was not attributable to a single identifiable event and caused time loss from full participation in training.

The anthropometric characteristics of each athlete were assessed both prior to the start of winter training (September) and at the end of the season (May). In total, four measurements were performed during the 2 years, and the mean was calculated including the biological maturity status. This was assessed using the noninvasive method of calculating the age at peak height velocity (APHV) with sex-specific prediction equations. ${ }^{23}$ The good validity of this method was shown in an examination of youth ski racers by comparing the APHV method with the estimation of skeletal age using X-rays of the left wrist. ${ }^{24}$ Following the approach used by Deprez et $\mathrm{al}^{25}$ the athletes were then divided into three maturity groups (early-, normal-, or late-maturing) based on the mean \pm standard deviation (SD) of the APHV of the total sample (separated by sex; normal, APHV within mean $\pm \mathrm{SD}$; early, APHV $<$ mean $-\mathrm{SD}$; late, APHV $>$ mean $+\mathrm{SD}$ ).

The birth dates of all participants were collected and categorized into four relative age quartiles $(\mathrm{Q} 1-\mathrm{Q} 4)$ according to their birth months (Q1, January-March; Q2, April-June; Q3, July-September; Q4, October-December). The anthropometric data of the participants separated by sex are presented in Table 1 (mean of four measurements). The study was performed according to the Declaration of Helsinki and was approved by the Institutional Review Board of the Department of Sport Science of the University of Innsbruck and the Board for Ethical Questions of the University of Innsbruck.

\section{Statistical analyses}

All data were controlled for double reporting. Descriptive statistics are presented as mean \pm SD for continuous variables

Table I Anthropometric data (mean \pm SD) of participants according to sex

\begin{tabular}{lll}
\hline Anthropometrics & Males $(\mathbf{n}=\mathbf{5 I})$ & Females $(\mathbf{n = 3})$ \\
\hline Age $($ years $)$ & $1 \mathrm{I} .6 \pm \mathrm{I} .5$ & $\mathrm{II} .8 \pm \mathrm{I} .3$ \\
Height $(\mathrm{cm})$ & $153.4 \pm 9.0$ & $154.9 \pm 7.7$ \\
Weight $(\mathrm{kg})$ & $42.3 \pm 8.1$ & $43.8 \pm 7.9$ \\
BMI $\left(\mathrm{kg} / \mathrm{m}^{2}\right)$ & $17.8 \pm \mathrm{I} .9$ & $18.1 \pm 2.2$ \\
APHV (years) & $13.7 \pm 0.5$ & $12.0 \pm 0.5$ \\
\hline
\end{tabular}

Abbreviations: BMI, body mass index; APHV, age at peak height velocity; SD, standard deviation. and as frequency counts and percentages for categorical variables. Categorical variables, such as sex-specific differences and differences between the three groups of maturity status and athletes of the four relative age quartiles, were assessed by $\chi^{2}$-tests. Additionally, odds ratios (ORs) and 95\% confidence intervals $(95 \%$ CIs) were calculated. The injury rate was calculated as the number of injured ski racers divided by number of ski racers (separated by sex). The incidence of traumatic injuries per 1,000 hours of training exposure (athletic and skiing-specific) was assessed by the number of injuries divided by total number of hours of exposure multiplied by 1,000. The prevalence rates of illness and overuse injuries were also calculated. ${ }^{22,26}$ The level of significance was set at $P<0.05$. All calculations were performed using SPSS 23.0 (IBM Corporation, Armonk, NY, USA).

\section{Results}

At the beginning of the study, 85 athletes were enrolled. Throughout the 2-season study period, three athletes left the school. The 82 remaining athletes reported 266 medical problems in total.

\section{Training exposure}

Throughout the two-season study period, 2,020 training sessions (922 skiing, 1,098 athletic) were analyzed. A total mean exposure time of 738 hours (261 hours of athletic training, 477 hours of skiing-specific training) was recorded. A mean of $2.9( \pm 0.1)$ skiing sessions and $1.9( \pm 0.1)$ athletic sessions were performed per week; this corresponded to $12( \pm 0.9)$ hours of skiing training and $3.7( \pm 0.5)$ hours of athletic training per week, as well as $236.6( \pm 17.8)$ hours of skiing training and $130.1( \pm 17.2)$ hours of athletic training per season. The athletes participated in a mean of $17( \pm 6.3)$ races per season.

\section{Traumatic injuries}

In total, 52 traumatic injuries were reported by $42.7 \%$ of the athletes ( $n=35,14$ females, 21 males; Figure 1), which produced a rate of 0.63 injuries/athlete and an incidence of 0.86 traumatic injuries per 1,000 hours of training (males, 0.9/1,000 hours of training; females, 0.79/1,000 hours of training). Among all female athletes with a traumatic injury, $7 \%(n=1)$ reported two injuries; all other injured females sustained one traumatic injury during the two-season study period. Among injured male athletes, $71.4 \%(\mathrm{n}=15)$ reported one, $23.8 \%(n=5)$ reported two, and $4.8 \%(n=1)$ sustained three traumatic injuries. The month with the highest injury rate was January (26.9\%), followed by November and June (13.5\% each). Table 2 presents the distribution of injury type 


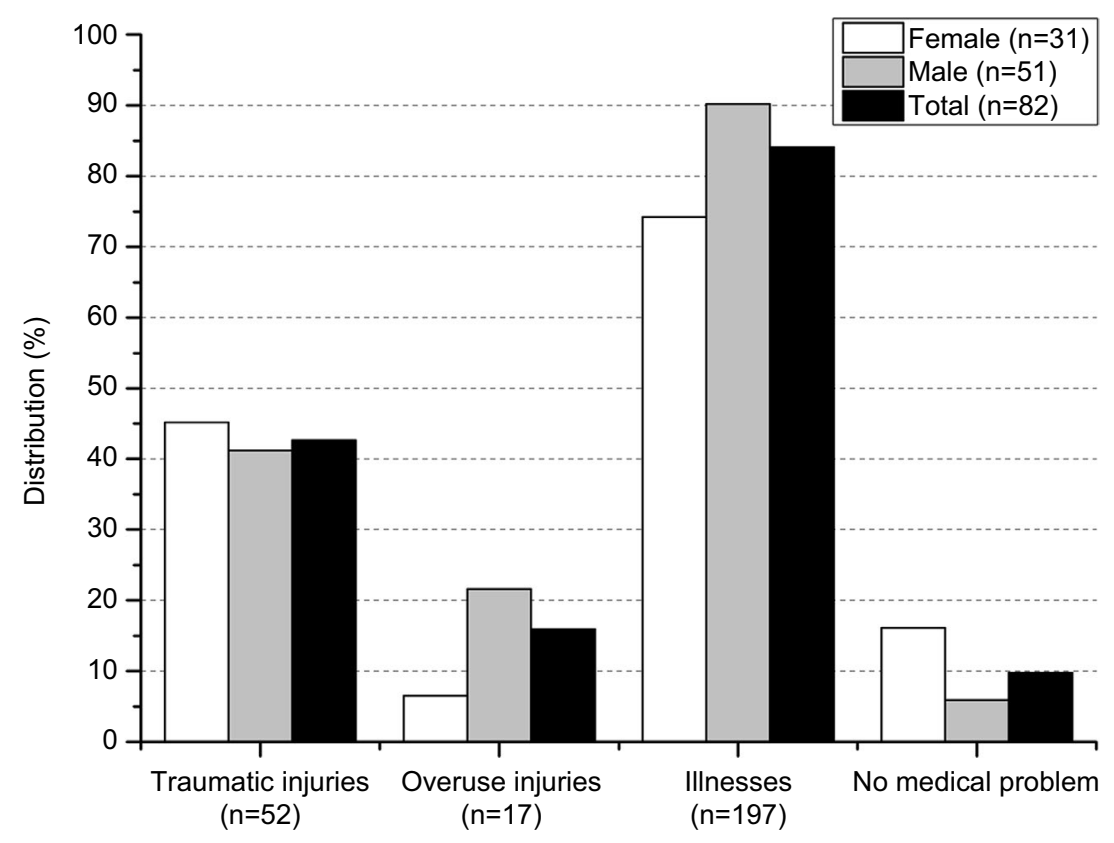

Figure I Traumatic and overuse injuries of the total sample, separated by sex (percentage of affected athletes of total sample).

Table 2 Distribution of injury type and injured body part

\begin{tabular}{|c|c|c|c|}
\hline \multirow{2}{*}{$\begin{array}{l}\text { Type and localization } \\
\text { of injury }\end{array}$} & \multicolumn{2}{|c|}{ Category of injury, n (\%) } & \multirow[t]{2}{*}{ Total, n (\%) } \\
\hline & Overuse & Traumatic & \\
\hline \multicolumn{4}{|l|}{ Type of injury } \\
\hline Muscle and tendon & $16(94.1)$ & $9(17.3)$ & $25(36.2)$ \\
\hline Ligament & 0 & $13(25)$ & $13(18.8)$ \\
\hline Joint & I (5.9) & $3(5.8)$ & $4(5.8)$ \\
\hline Bone & 0 & $24(46.1)$ & $24(34.8)$ \\
\hline Brain/spinal cord & 0 & $3(5.8)$ & $3(4.4)$ \\
\hline \multicolumn{4}{|l|}{ Injured body part } \\
\hline Head/neck & 0 & $3(5.8)$ & $3(4.4)$ \\
\hline Upper extremity & 0 & $9(17.4)$ & $9(13.1)$ \\
\hline Trunk/back & I (5.9) & I (I.9) & $2(2.9)$ \\
\hline Knee & $14(82.3)$ & $19(36.5)$ & $33(47.8)$ \\
\hline Hip/thigh & $2(11.8)$ & $5(9.6)$ & $7(10.1)$ \\
\hline Lower leg/foot/ankle & 0 & $15(28.8)$ & $15(2 \mid .7)$ \\
\hline
\end{tabular}

and injured body parts. Most of the traumatic injuries affected the bones $(46.1 \%)$, resulting in fractures and bone bruises, as well as ligament injuries (25\%). The knee was the most commonly injured body part (36.5\%), followed by the lower extremities (28.8\%). Only one male athlete sustained an ACL rupture. More than half of the injuries occurred in training sessions (57.7\%), followed by leisure time activities $(26.9 \%)$ and competition $(9.6 \%) ; 5.8 \%$ could not be classified. Most of the traumatic injuries $(44.2 \%)$ were classified as moderate (Figure 2). No significant differences were observed in the frequencies of traumatic injuries between males and females ( $P=0.617$; Figure 1$)$, the three groups of maturity $(P=0.643$; Figure 3$)$, or the four relative age quartiles ( $P=0.3$; Figure 4$)$.

\section{Overuse injuries}

In total, 17 overuse injuries were reported by 13 athletes (10.7\%, 2 females, 11 males; Figure 1), with a rate of 0.21 overuse injuries/athlete and a prevalence of 0.28 overuse injuries/1,000 hours of training (males, 0.4/1,000 hours of training; females, 0.09/1,000 hours of training). Most of the overuse injuries had occurred for the first time, while only $23.1 \%$ were defined as recurrent. The most commonly affected body part was the knee $(82.3 \%)$, and nearly all overuse injuries comprised tendon and muscle structures (94.1\%; Table 2). May and September (23.5\% each) were the months with the highest overuse-injury rates. All overuse injuries caused time loss, and most were classified as moderate $(47.1 \%)$ or severe $(17.6 \%$; Figure 2$)$. No significant differences were present in the frequencies of overuse injuries between males and females $(P=0.81$; Figure 1$)$, the three groups of maturity ( $P=0.696$; Figure 3 ), or among the four relative age quartiles $(P=0.22$; Figure 4$)$.

\section{Illnesses}

A total of 69 athletes $(84.1 \%, 23$ females, 46 males; Figure 1) were affected by 197 illnesses, with a rate of 2.4 illnesses/athlete. Most of the illnesses were respiratory tract infections $(66.4 \%)$, followed by gastrointestinal problems (18.7\%), and headache/dizziness (10.7\%). The months with the highest prevalence of illnesses were January (15.2\%) and April (12.7\%). Most of the illnesses were categorized as minimal (61.9\%; Figure 2). A quarter of illnesses required 


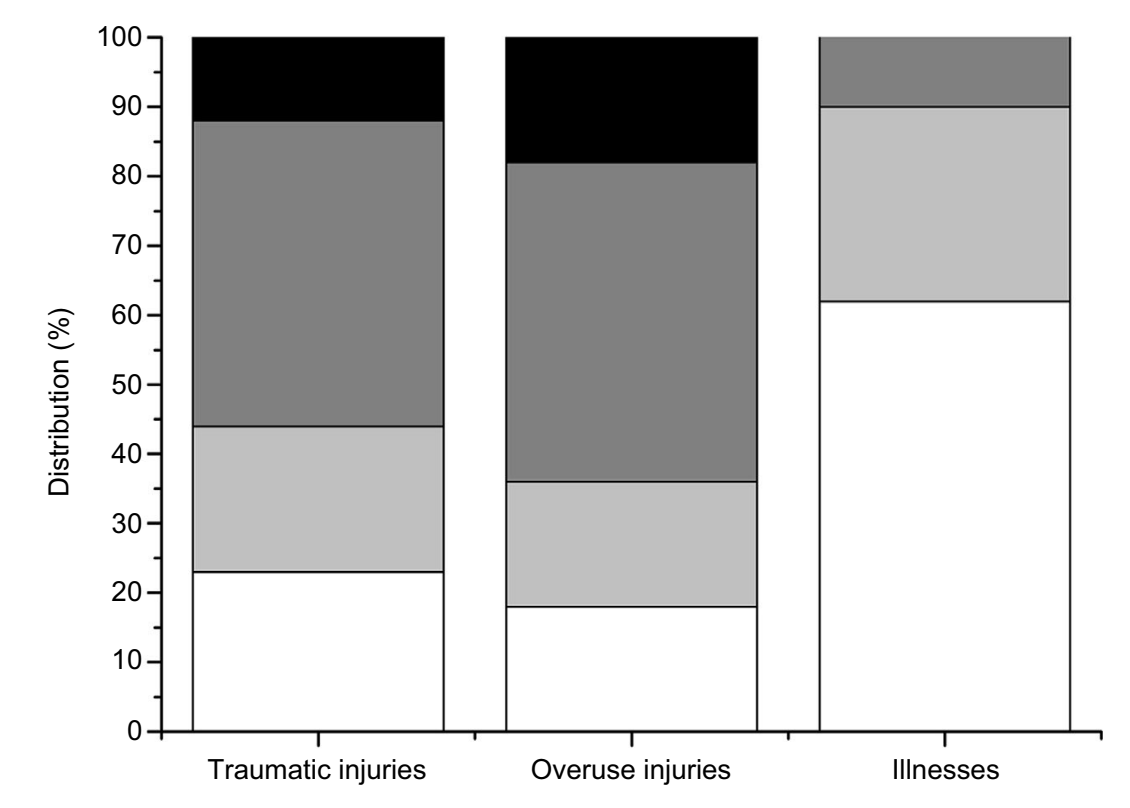

Severe (>28 days) $\square$ Moderate (8-28 days) $\square$ Mild (3-7 days)

Minimal (1-3 days)

Figure $\mathbf{2}$ Severity of traumatic and overuse injuries as well as illnesses.

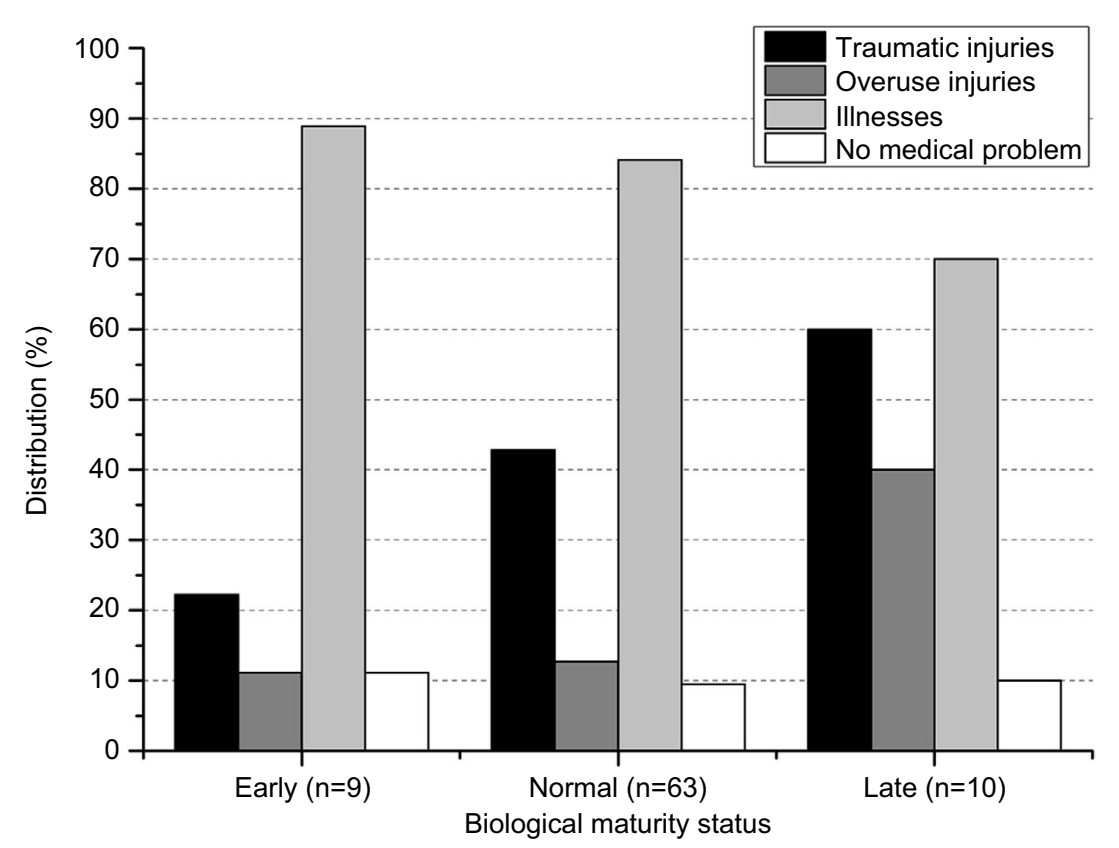

Figure 3 Traumatic injuries, overuse injuries, and illnesses separated by biological maturity status (percentages of affected athletes in each category).

medical attendance, and $31 \%$ caused a fever of at least 1 day. No significant differences were present in the frequency of illnesses between males and females ( $P=0.554$; Figure 1), the three groups of maturity ( $P=0.931$; Figure 3$)$, or among the four relative age quartiles ( $P=0.752$; Figure 4$)$.

\section{Absence of medical problems}

Among all athletes, eight $(9.8 \%$, three males, five females;

Figure 1) reported no medical problems. Female athletes had a significantly higher chance of having no medical problems $\left(\chi^{2}=5.775\right.$, OR $0.85,95 \%$ CI $\left.0.48-1.5 ; P=0.016\right)$. No significant differences were present in the frequencies of "no medical problem" among the three groups of maturity $(P=0.761$; Figure 3$)$ or the four relative age quartiles $(P=0.106$; Figure 4$)$. When the first and the last relative age quartile were compared, Q4 athletes had a significantly higher chance of having no medical problems $\left(\chi^{2}=5.74\right.$, OR 0.38 , 95\% CI 0.13-1.05; $P=0.017$ ). 


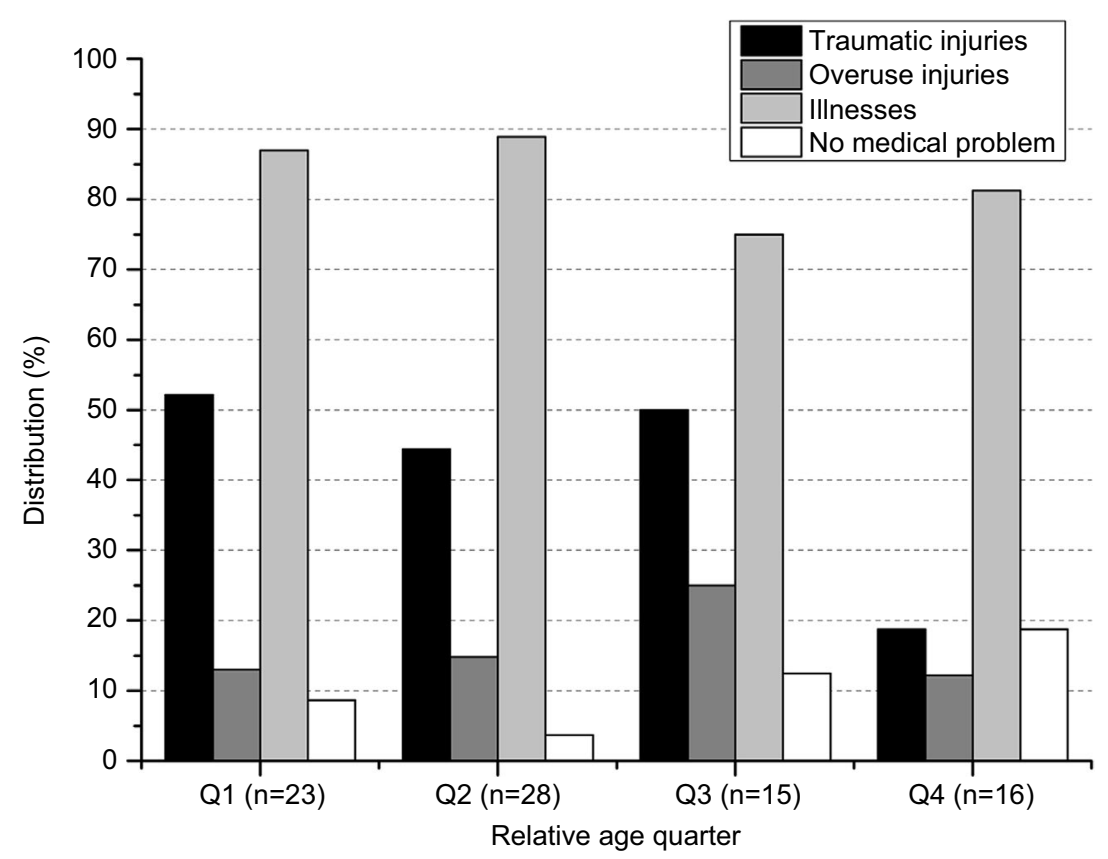

Figure 4 Traumatic injuries, overuse injuries, and illnesses separated by relative age quarter (percentage of affected athletes in each category).

\section{Discussion}

The present study was the first prospective study on injury incidence and severity involving youth alpine ski racers younger than 15 years, as suggested by Spörri et al. ${ }^{1}$ Relatively low incidence of traumatic and overuse injuries and comparably high prevalence of illnesses were revealed. No sex-specific differences were present, except for females presenting a higher chance of having no medical problems. No significant differences were found between differing maturity groups and relative age quartiles. However, Q4 athletes had a significantly higher chance of having no medical problems than Q1 athletes, and only small percentages of relatively younger (Q4) and early-maturing athletes were affected by traumatic and overuse injuries.

To date, most studies on injury and illness rates have investigated major events, with data acquisition over only a few days. ${ }^{27-29}$ However, to understand the epidemiology of sport-specific health problems better, a long-term data analysis of the amount of time spent in training is required. In the present study, the numbers of training sessions and hours (including off-snow training) were regularly documented for each athlete over the entire study period; therefore, the results on incidence and prevalence reflect the exact exposure data.

\section{Traumatic and overuse injuries}

The incidence and rate of traumatic injuries ( 0.86 injuries/1,000 hours of training, 0.63 injuries/athlete) were smaller than in studies at both the youth (1.7 injuries/1,000 ski hours) ${ }^{8}$ and elite levels (36.7 injuries/100 athletes). ${ }^{1-4}$
Consistent with other studies, ${ }^{8,11}$ no sex-specific differences were present in the number of traumatic injuries among youth ski racers, which may be associated with similar training-load exposure (skiing-specific and athletic training sessions were conducted together for males and females). In contrast, at the elite level, male athletes had a higher injury risk in general. ${ }^{4}$ A possible explanation could be the more demanding course settings, diverse slope characteristics, and higher speeds in elite male ski racing compared to female ski racing, whereas at the youth level no such differences are apparent. Furthermore, it needs to be considered that the competition rate in youth athletes is much lower compared to the elite level.

The knee was the most commonly affected body part (36.5\%) followed by the lower extremities $(28.8 \%)$. This finding is consistent with the results of studies of World Cup athletes (knee 35.6\%, lower leg 11.5\%) 2.6 $^{2,6}$ and youth athletes (knee 41\%). ${ }^{8}$ Previous studies have shown a high incidence of ACL ruptures in competitive alpine ski racers; ${ }^{2,6,30}$ however, in the present study, only one male athlete suffered an ACL rupture. It can be assumed that the elastic properties of tendon structures in the growing athlete are higher and thus more compliant compared to full-grown athletes. ${ }^{31}$ Most of the traumatic injuries were classified as moderate (44.2\%), which is comparable to the results of Hildebrandt and Raschner (46\%). ${ }^{11}$ However, traumatic injuries at the World Cup level were mostly classified as severe $(35.6 \%){ }^{4}$ A possible reason for these contrasting results could be the retrospective study design at the elite level; it could be assumed that not all minimal or moderate 
injuries were able to be assessed, because of missing data. A novel finding was the relatively high number of bone fractures, including physeal fractures $(46.1 \%)$. Two possible explanations exist. First, the age of peak bone mass is later than APHV by up to 1 year, which could lead to a higher vulnerability to bone fractures in athletes younger than 16 years. ${ }^{32}$ Second, the physis is weaker than ligaments; therefore, fractures are more likely to occur than a rupture. Even though this injury is typical in children, further investigations are necessary. ${ }^{32}$

High training volumes, overscheduling, and the adolescent growth spurt represent risk factors for overuse injuries. ${ }^{33}$ Epidemiological studies of overuse injuries in alpine ski racing are rare, especially those involving youth ski racers prior to or during puberty. A 2-year retrospective analysis of adolescent ski racers reported that more than $50 \%$ sustained at least one overuse injury. ${ }^{11}$ In the present study, however, only 17 overuse injuries were reported. Therefore, an incidence of 0.28 injuries/1,000 hours of training was assessed. No sex-specific differences were found, although females had descriptively lower overuse-injury incidence ( 0.09 versus 0.4 injuries/1,000 hours of training); this finding is consistent with the results of Hildebrandt and Raschner. ${ }^{11}$ However, it can be assumed that the prevalence of overuse injuries was underestimated. According to DiFiori, ${ }^{34}$ overuse injuries can be classified into five stages. In the present study, only stage five was considered, which includes symptoms that cause an absence from full training. Although physiotherapists verified the overuse injuries, their classification is difficult, because overuse injuries do not have a precise onset.

In the present study, few reported overuse injuries were recurrent $(23.1 \%)$ but classified as moderate $(47.1 \%)$ or severe (17.6\%). Therefore, the youth athletes had sufficient time to recover, and the pressure to return to training and competition or to train despite symptoms was not as high as it probably could have been for adolescent athletes. The most commonly affected body part was the knee $(82.3 \%)$, which is consistent with previous findings for youth alpine ski racing ${ }^{11}$ and other types of youth sport. ${ }^{9,26}$ Growing athletes suffer from unspecified but self-limiting knee problems independently of the type of sport. The growth rate of the apophysis is slower than that of the epiphyseal plate, leading to problems of the interface between bone and ligaments. Most overuse injuries are classified as typical apophysitis, such as Osgood-Schlatter disease. ${ }^{35}$ Despite the high number of fractures included as traumatic injuries, no stress fractures occurred. The highest overuse-injury rates were reported at the beginning of training following the holiday (September) and after changes in training (May); therefore, during these periods, low-impact training should be performed to enable the passive structures to adapt.

In total, relatively low rates of both traumatic and overuse injuries were revealed. Both the close cooperation with the coaches of the ski boarding school and the discussion about injury prevention in youth ski racing prior to the injury-prevention implementation at the beginning of the study might have shifted coaches' awareness. According to LaBella and Myer, ${ }^{36}$ injury prevention in youths should include appropriate time for complementary training instead of focusing only on sport-specific training. Therefore, a regular physiotherapy examination was implemented in the training process of the ski boarding school. Based on these examinations, individual, complementary training sessions were applied to compensate for or prevent muscular imbalances and asymmetries in the young athletes. Additionally, a screening program with potentially preventive effects was performed in the ski boarding school. The program was conducted twice per year to identify pathophysiological conditions and to minimize intrinsic risk factors, such as joint instability, muscle-strength asymmetry, and muscle weakness. Therefore, it can be assumed that all these measures contributed to the relatively low traumatic and overuse-injury incidence and prevalence compared to the adolescent and elite levels.

\section{Illnesses}

Illnesses represented the most common medical problem in the present study. During the two-season study period, $84.1 \%$ of all athletes were ill at least once, which corresponded to an illness rate of 2.4 illnesses/athlete. Most of the illnesses were respiratory tract infections $(66.4 \%)$, which is consistent with the results of youth tennis $(60 \%)^{26}$ and those of adolescent athletes at the Winter Youth Olympic Games in $2016(84 \%){ }^{29}$ In the present study, $62 \%$ of illnesses were categorized as minimal, with a time loss of 1-3 days. No sex-specific differences were found in the prevalence of illnesses; however, at the Winter Youth Olympic Games in 2016, a significantly higher proportion of illnesses was reported among female athletes. ${ }^{29}$ It can be assumed that the comparable illness rates for males and females may be associated with similar training-load exposure, because training was conducted together for males and females. Most of the illnesses occurred in January or April after short holidays. However, it is important to consider that these findings are based on a group of young pupils; as such, the combination of sport and life at the boarding school can contribute to a higher risk of infecting one another. 


\section{Biological maturity status}

The distribution of normal- (77\%), early- (11\%), and latematuring (12\%) athletes did not significantly differ from the expected normal distribution. This finding is consistent with the distribution of youth ski racers (10-15 years old) participating in provincial races in Austria. ${ }^{17}$ No significant differences were observed in the occurrence of injuries and illnesses between differing maturity groups, which is consistent with a study of youth soccer ${ }^{14}$ in which differences were found only in injury severity (late-maturing athletes had a higher incidence of severe injuries) and types of injury, but not in injury incidence. Mismatches in biological maturity between young athletes have been suggested to contribute to higher injury risk. ${ }^{37}$ Interestingly, in the present study $60 \%$ of all late-maturing athletes had a traumatic injury and $40 \%$ an overuse injury, whereas only $22 \%$ of all early-maturing athletes had a traumatic injury and $11 \%$ an overuse injury. However, the differences were not significant, but a trend can be assumed wherein biological maturity status influences injury risk in youth ski racers. The small sample sizes in the groups of early- and late-maturing athletes and the generally low rates of injuries might explain the insignificant result. Nevertheless, these findings revealed that biological maturity status should be considered in the training process of youth ski racers to prevent traumatic and overuse injuries, especially in late-maturing athletes.

\section{Relative age}

In Canadian youth ice hockey, relatively older athletes were shown to be at higher risk of injury, which additionally increased as the level of play became more competitive. ${ }^{15}$ In the present study, no significant differences were found. However, relatively younger athletes had a significantly higher chance of having no medical problems than Q1 athletes. Additionally, only $19 \%$ of the Q4 athletes had a traumatic injury; the percentages of the other quartiles were much higher (Q1 52\%, Q2 44\%, Q3 50\%). Although not significant, these results demonstrate that relatively younger athletes, who may have counteracted their relative age disadvantage if they were more mature and possibly at a higher level of physical fitness, seem to have a lower risk of traumatic injuries than their relatively older counterparts, which would again be in line with the results in Canadian youth ice hockey. ${ }^{15}$ A high percentage of early-maturing athletes (41\%) was found among relatively younger youth ski racers selected for national final races. ${ }^{17}$ Therefore, the present findings could confirm that athletes of the last relative age quartile might be more mature and may thus have lower injury risk. However, further research is necessary.

\section{Conclusion}

A relatively low incidence of traumatic and overuse injury and a high prevalence of illness were found among elite youth alpine ski racers under 15 years of age. No significant sex-specific differences were present, although females reported a descriptively lower overuse-injury rate than males. Relatively younger and early-maturing athletes sustained a comparatively low number of traumatic and overuse injuries. Therefore, biological maturity status should be considered in the training process to help prevent injuries. Both the prospective study design and implementation of the training-and-injury database seem to offer reliable data. The injury-prevention strategies implemented in the ski boarding school appear to have contributed to low incidences of traumatic and overuse injuries. Further investigations with larger sample sizes should be performed. Additionally, following the multistage sequence by van Mechelen et al, ${ }^{7}$ the next step should involve evaluation of the detailed causes of injury, risk factors, and assessment of mechanisms in a cohort of youth ski racers.

\section{Strengths and limitations}

Several strengths of the present study can be mentioned. It was the first study with regard to injury incidence and severity and illness prevalence involving youth ski racers younger than 15 years. The main strength is the prospective study design to avoid recall bias. Additionally, the exact time durations spent in skiing specific and athletic training were regularly documented, whereas in other studies injury incidence often could only be calculated per hours of races and off-snow training was not considered. Until now, no studies have been published with regard to illnesses in youth ski racing, although illnesses can inhibit training adaptations, which is another strength of the present study. The two aspects of biological maturity status and relative age were new approaches in injury-prevention research in alpine ski racing.

The main limitation of the present study was the small sample size. This is explained by the fact that there were no more youth ski racers available at the ski boarding school. However, the group of youth ski racers investigated was a cohort of high-level athletes who represented the most talented athletes of the given age and region. In the future, a similar study should be performed involving a larger sample size.

\section{Acknowledgments}

The authors would like to thank all of the athletes and their parents for participating in the study. Additionally, many 
thanks go to the ski boarding school, headmaster and head coach, and all coaches for their cooperation.

\section{Disclosure}

The authors report no conflicts of interest in this work.

\section{References}

1. Spörri J, Kröll J, Gilgien M, Müller E. How to prevent injuries in alpine ski racing: what do we know and where do we go from here? Sports Med. 2017;47(4):599-614.

2. Flørenes TW, Bere T, Nordsletten L, Heir S, Bahr R. Injuries among male and female World Cup alpine skiers. Br J Sports Med. 2009;43(13): 973-978.

3. Haaland B, Steenstrup SE, Bere T, Bahr R, Nordsletten L. Injury rate and injury patterns in FIS World Cup Alpine skiing (2006-2015): have the new ski regulations made an impact? Br J Sports Med. 2016;50(1):32-36.

4. Bere T, Flørenes TW, Nordsletten L, Bahr R. Sex differences in the risk of injury in World Cup alpine skiers: a 6-year cohort study. Br J Sports Med. 2013;48(1):36-40.

5. Flørenes TW, Nordsletten L, Heir S, Bahr R. Recording injuries among World Cup skiers and snowboarders: a methodological study. Scand J Med Sci Sports. 2011;21(2):196-205.

6. Flørenes TW, Nordsletten L, Heir S, Bahr R. Injuries among World Cup ski and snowboard athletes. Scand J Med Sci Sports. 2012;22(1):58-66.

7. van Mechelen W, Hlobil H, Kemper HC. Incidence, severity, aetiology and prevention of sports injuries: a review of concepts. Sports Med. 1992;14(2):82-99.

8. Westin M, Alricsson M, Werner S. Injury profile of competitive alpine skiers: a five-year cohort study. Knee Surg Sports Traumatol Arthrosc. 2012;20(6):1175-1181.

9. Leppänen M, Pasanen K, Kujala UM, Parkkari J. Overuse injuries in youth basketball and floorball. Open Access J Sports Med. 2015;6: 173-179.

10. Drew MK, Finch CF. The relationship between training load and injury, illness and soreness: a systematic and literature review. Sports Med 2016;46(6):861-883.

11. Hildebrandt $C$, Raschner $C$. Traumatic and overuse injuries among elite adolescent alpine skiers: a two-year retrospective analysis. Int Sport Med J. 2013;14(4):245-255.

12. Rachbauer F, Sterzinger W, Eibl G. Radiographic abnormalities in the thoracolumbar spine of young elite skiers. Am J Sports Med. 2001; 29(4):446-449.

13. Spörri J, Kröll J, Haid C, Fasel B, Müller E. Potential mechanisms leading to overuse injuries of the back in alpine ski racing. Am J Sports Med 2015;43(8):2042-2048.

14. Le Gall F, Carling C, Reilly T. Biological maturity and injury in elite youth football. Scand J Med Sci Sports. 2007;17(5):564-572.

15. Wattie N, Cobley S, Macpherson A, Howard A, Montelpare WJ, Baker J. Injuries in Canadian youth ice hockey: the influence of relative age. Pediatrics. 2007;120(1):142-148.

16. Müller L, Müller E, Raschner C. The relative age effect in alpine ski racing: a review. Talent Dev Excell. 2016;8(1):3-14.

17. Müller L, Müller E, Hildebrandt C, Raschner C. Biological maturity status strongly intensifies the relative age effect in alpine ski racing. PLoS One. 2016;11(8):e0160969.
18. Huxley DJ, O'Connor D, Healey PA. An examination of the training profiles and injuries in elite youth track and field athletes. Eur J Sport Sci. 2014;14(2):185-192.

19. Østerås H, Garnæs KK, Augestad LB. Prevalence of musculoskeletal disorders among Norwegian female biathlon athletes. Open Access $J$ Sports Med. 2013;4:71-78.

20. Brooks JH, Fuller CW. The influence of methodological issues on the results and conclusions from epidemiological studies of sports injuries: illustrative examples. Sports Med 2006;36(6):459-472.

21. Junge A, Engebretsen L, Alonso JM, et al. Injury surveillance in multisport events: the International Olympic Committee approach. $\mathrm{Br} \mathrm{J}$ Sports Med. 2008;42(6):413-421.

22. Clarsen B, Rønsen O, Myklebust G, Flørenes TW, Bahr R. The Oslo Sports Trauma Research Center questionnaire on health problems: a new approach to prospective monitoring of illness and injury in elite athletes. Br J Sports Med. 2014;48(9):754-760.

23. Mirwald RL, Baxter-Jones AD, Bailey DA, Beunen GP. An assessment of maturity from anthropometric measurements. Med Sci Sports Exerc. 2002;34(4):689-694.

24. Müller L, Müller E, Hildebrandt C, Kapelari K, Raschner C. [The assessment of biological maturation for talent selection: which method can be used?] Sportverletz Sportschaden. 2015;29(1):56-63. German.

25. Deprez D, Coutts AJ, Deconinck F. Relative age, biological maturation and anaerobic characteristics in elite youth soccer players. Int J Sports Med. 2013;34(10):897-903.

26. Pluim BM, Fuller CW, Batt ME, et al. Consensus statement on epidemiological studies of medical conditions in tennis. Br J Sports Med. 2009; 43(12):893-897.

27. Engebretsen L, Steffen K, Alonso JM, et al. Sports injuries and illnesses during the Winter Olympic Games 2010. Br J Sports Med. 2010; 44(11):772-780.

28. Soligard T, Steffen K, Palmer-Green D, et al. Sports injuries and illnesses in the Sochi 2014 Olympic Winter Games. Br J Sports Med. 2015; 49(7):441-447.

29. Steffen K, Moseid CH, Engebretsen L, et al. Sports injuries and illnesses in the Lillehammer 2016 Youth Olympic Winter Games. Br J Sports Med. 2017;51(1):29-35.

30. Raschner C, Platzer HP, Patterson C, Werner I, Huber R, Hildebrandt C. The relationship between ACL injuries and physical fitness in young competitive ski racers: a 10-year longitudinal study. Br J Sports Med. 2012; 46(15):1065-1071.

31. Kubo K, Kanehisa H, Kawakami Y, Fukanaga T. Growth changes in the elastic properties of human tendon structures. Int J Sports Med. 2001 22(2):138-143.

32. Klentrou P. Influence of exercise and training on critical stages of bone growth and development. Pediatr Exerc Sci. 2016;28(2):178-186.

33. DiFiori JP, Benjamin HJ, Brenner JS, et al. Overuse injuries and burnout in youth sports: a position statement from the American Medical Society for Sports Medicine. Br J Sports Med. 2014;48(4):287-288.

34. DiFiori JP. Evaluation of overuse injuries in children and adolescents. Curr Sports Med Rep. 2010;9(6):372-378.

35. Caine D, DiFiori J, Maffulli N. Physeal injuries in children's and youth sport: reason for concerns? Br J Sports Med. 2006;40(9):749-760.

36. LaBella CR, Myer GD. Youth sports injury prevention: keep calm and play on. Br J Sports Med. Epub 2016 Dec 5.

37. Steffen K, Engebretsen L. More data needed on injury risk among young elite athletes. Br J Sports Med. 2010;44(7):485-489. 


\section{Publish your work in this journal}

The Open Access Journal of Sports Medicine is an international, peer-reviewed, open access journal publishing original research, reports, reviews and commentaries on all areas of sports medicine. The journal is included on PubMed. The manuscript management system is completely online and includes a very quick and fair

Submit your manuscript here: http://www.dovepress.com/open-access-journal-of-sports-medicine-journal

peer-review system. Visit http://www.dovepress.com/testimonials.php to read real quotes from published authors. 